\title{
CONSTRUÇÃO DA IMAGEM DE SI E DO OUTRO: CARTAS DE VIAGEM DE JAN HUS PARA CONSTANÇA $(1414)^{1}$
}

THIAGO BORGES DE AGUIAR

Universidade Metodista de Piracicaba

RESUMO O clérigo Jan Hus (1369?-1415), que estava no exílio desde 1412, inicia, no final do ano de 1414, uma viagem para a cidade de Constança, onde se realizaria um Concílio. Ao longo dessa viagem, ele escreveu uma pequena quantidade de cartas nas quais, entre outras coisas, narra os eventos do percurso, defende suas opiniões e posições, analisa as questões de seu contexto histórico e, por meio dessas ações, constrói uma imagem de si e do outro (de diversos outros). Este artigo se propõe a analisar a construção dessas imagens de si e do outro e suas modificações, ao longo de sete cartas escritas, pouco antes, durante e logo depois da viagem. A análise é subsidiada por estudos sobre cartas e histórias de vida, com inspiração teórica nas reflexões historiográficas de Carlo Ginzburg, e contextualizada a partir das pesquisas sobre Hus, realizadas por Matthew Spinka. O texto dialoga com nossas pesquisas recentes sobre a temática. Concluise pela mudança da imagem de si, de alguém que estava diante da morte para alguém que se sente forte e em luta, pela transformação da imagem inicial dos alemães como inimigos e pela construção de diversas imagens dos diferentes destinatários como sujeitos que necessitam das palavras de Hus.

Palavras-chave: Cartas. Século XV. Histórias de vida. Narrativas de viagem.

\section{ABSTRACT CONSTRUCTING THE IMAGES OF ONESELF AND THE OTHER: JAN HUS' LETTERS FROM HIS TRIP TO CONSTANCE (1414)}

The clergyman Jan Hus (1369? -1415), who had been in exile since 1412, began, in the end of 1414 , a trip to the city of Constance, where a Council would be held. Throughout the trip, he wrote a small amount of letters in which, among other things, he narrates the events of the

1 Este trabalho contou com apoio financeiro da Fundação de Amparo à Pesquisa do Estado de São Paulo (FAPESP) e Conselho Nacional de Desenvolvimento Científico e Tecnológico (CNPq). 
ride, defends his opinions and positions, analyzes issues of his historical context and, through these actions, builds an image of himself and of other (of several others). This article is presented as a study on the construction of those images and their modifications during the trip. The analysis is subsidized by studies on letters and life histories, with theoretical inspiration in the historical reflections of Carlo Ginzburg and contextualized from the researches on Hus conducted by Matthew Spinka. The text dialogues with our recent researches on the subject. It concludes that there has been a change on his self-image from someone who was about to die to someone who feels strong and struggling, a transformation in the initial image of the Germans as enemies and a construction of several images of different addressees as subjects needing Hus' words.

Keywords: Letters. Fifteenth Century. Life Stories. Travel Narratives.

RESUMEN CONSTRUCCIÓN DE LA IMAGEN DE SÍ Y DEL OTRO:

\section{CARTAS DE VIAJE DE JAN HUS PARA LA CONSTANZA} (1414)

El clérigo Jan Hus (1369? -1415), que estaba en el exilio desde 1412, inicia, a finales del año 1414, un viaje a la ciudad de Constanza, donde se celebraría un Concilio. A lo largo de ese viaje, escribió una pequeña cantidad de cartas en las que, entre otras cosas, narra los acontecimientos del recorrido, defiende sus opiniones y posiciones, analiza las cuestiones de su contexto histórico y, por medio de esas acciones, construye una imagen de sí y del otro (de varios otros). Este artículo se propone analizar la construcción de esas imágenes de sí y del otro y sus modificaciones, a lo largo de siete cartas escritas, poco antes, durante y poco después del viaje. El análisis es subsidiado por estudios sobre cartas e historias de vida, con inspiración teórica en las reflexiones historiográficas de Carlo Ginzburg y contextualizada a partir de las investigaciones sobre Hus, realizadas por Matthew Spinka. El texto dialoga con nuestras investigaciones recientes sobre la temática. Se concluye por el cambio de la imagen de sí, de alguien que estaba ante la muerte para alguien que se siente fuerte y en lucha, por la transformación de la imagen inicial de los alemanes como enemigos y por la construcción de diversas imágenes de los diferentes destinatarios como sujetos que necesitan las palabras de Hus.

Palabras clave: Cartas. Siglo XV. Historias de vida. Narrativas de viaje. 
Jan Hus foi um clérigo cristão tcheco do século XV, professor da Universidade de Praga que morreu pela fogueira, em 6 de julho de 1415, na cidade de Constança, acusado de ser um heresiarca. Na região das terras históricas tchecas (que incluíam, na época de Hus, Boêmia, Morávia e Silésia), sua morte desencadeou conflitos bélicos entre grupos posteriormente denominados hussitas e a Igreja Católica, nas décadas seguintes, e fortaleceu movimentos religiosos e nacionalistas nos séculos que se seguiram.

$\mathrm{O}$ ano tradicionalmente associado a seu nascimento, na cidade de Husinec, na Boêmia, é 1369, data apresentada em diversos textos, mas alguns historiadores calculam que ele tenha nascido entre 1372 e 1373, com maior probabilidade para o primeiro ano. Esse cálculo, porém, não possui prova documental (SPINKA, 1968, p. 21). Na primeira década do século XV, sua história de vida, já em Praga, inicia-se com sua ordenação clerical e o comando da Capela de Belém, passando pelas posições de professor e de reitor da Universidade Carlos (Univerzita Karlova), e culminando em um conjunto de acusações feitas contra ele pela alta hierarquia da Igreja.

Em um nível macro, Hus está inserido no contexto de um conflito teológico, envolvendo questões da Igreja, como opulência versus pobreza, venda de indulgências e disputas com relação aos significados da hierarquia eclesial. Vivia também perpassado por conflitos do âmbito político-religioso, como as disputas entre os reis tchecos (Venceslau e Sigismundo), entre os papas de Avignon e de Roma (e, posteriormente, o de Pisa), bem como entre clérigos, posicionando-se a favor ou contra o arcebispo de Praga e a hierarquia católica. Não menos importante era o secular convívio entre tchecos e alemães, permeado de conflitos que culminaram com a saída dos professores alemães da Universidade de Praga, em 1409, após disputas carregadas de elementos do campo da identidade, da filosofia e da política.

Em 1412, após três excomunhões e um interdito, Hus exilou-se de Praga, passando a viver em castelos no interior da Boêmia. $O$ interdito impedia que os serviços religiosos (que incluem missas, casamentos, batizados etc.) fossem realizados na cidade onde ele estivesse. Esse é um dos principais motivos que o levaram a deixar a cidade e sua atuação pastoral na Capela de Belém (onde fazia suas pregações em língua vernacular). Em exílio, escreve diversas cartas, textos pastorais e tratados religiosos, nos quais se defendia das acusações que sofria (que passavam por temas como "crítica excessiva" a algumas práticas clericais, desobediência à hierarquia e defesa das ideias de Wycliff), e buscava apoios de modo a manter uma rede de relações que sustentasse sua posição diante da excomunhão que recebera. Além disso, buscava explicar-se de modo que seus seguidores e fiéis compreendessem suas razões, e não se deixassem afetar pelas ações da alta hierarquia da Igreja.

Com a instauração do Concílio de Constança, em 1414, ele poderia apresentar sua defesa diante de uma das instituições mais fortes da igreja de então, perante "homens inteligentes", , podendo reverter a excomunhão e a interdição. Com o incentivo do rei Venceslau e o (suposto) apoio do rei Sigismundo, iniciou, no dia 11 de outubro, sua viagem para Constança. Durante a viagem, Hus escreve algumas cartas a partir das quais podemos observar o modo como ele constrói uma imagem de si e dos outros. Compreendermos essas imagens e o modo como elas realizam uma síntese, entre o micro e o macrocontexto, é o que nos propomos neste artigo.

2 Durante o período em que Hus esteve preso, ele recebe uma carta (com data de cerca de 20 de junho de 1415) de um membro do Concílio que pedia que Hus se submetesse, visto que lá havia muitos "homens inteligentes". 
No Brasil, são muito poucos os trabalhos a respeito de Jan Hus. Nos últimos dez anos, no âmbito da pesquisa universitária, os estudos disponíveis são resultantes de nossa própria investigação (AGUIAR, 2012 e outros trabalhos, incluindo em parcerias), ou em diálogo com o que produzimos (GUIMARÃES, 2011; NASCIMENTO, 2015), ou ainda apenas menções pontuais a seu respeito. ${ }^{3}$ Dentre estas últimas, as mais relevantes retratam-no como um pregador do século XV, precursor/antecessor dos Hussitas, de Lutero ou de Comenius, autor de um tratado sobre a Igreja, autor de uma cartilha, religioso cuja memória é resgatada nos séculos seguintes, personagem que morreu vítima de perseguição, mártir. Tratam-se, aqui, das imagens mais comuns difundidas a respeito de Hus, e todas elas aparecem como suporte a algum argumento ou narrativa sobre outro assunto ou sujeito, e referenciado apenas em bibliografia (e não em documentos).

Em língua inglesa, há maior produção a respeito de Hus. ${ }^{4}$ Um estado da arte (FUDGE, 2016) dessa produção foi publicado em 2016, por ocasião do aniversário de 600 anos (que ocorreu em 2015) da morte do clérigo tcheco. 0 texto de Fudge (2016) traz os principais nomes que publicaram livros sobre Hus, em inglês, avaliando suas principais fontes e contribuições. Não cabe aqui um mapeamento detalhado das quase cinquenta páginas daquele

3 Consultamos, para a escrita deste artigo, as bases Scielo, Educ@, a busca por assuntos na Plataforma Lattes e os 100 primeiros resultados da pesquisa Google Scholar em português. Neste levantamento, exceto pelos textos dos autores citados acima, não houve nenhum outro artigo em que Jan Hus fosse o objeto de investigação. Ele foi apenas mencionado como um personagem histórico para subsidiar alguma argumentação sobre outra questão. Nesse sentido, não há desenvolvimento de novo saber a respeito de sua figura nos textos encontrados nesse levantamento.

4 Não fizemos, para este artigo, levantamento de pesquisas em outras línguas, de modo a mapear exaustivamente as investigações a respeito de Hus no mundo. Para esta parte, nossa intenção é apenas destacar, em linhas gerais, de que modo este artigo se insere no âmbito destas pesquisas. artigo. Em linhas gerais, podemos afirmar que o autor apresenta a construção tradicional das duas principais imagens de Hus (o herege, corretamente excomungado da Igreja, e o mártir, injustamente condenado) e os percursos da historiografia hussita em tcheco (František Palacký, Václav Novotný, Vlastimil Kybal, Jan Sedlák, František M. Bartoš, entre outros), a controvérsia levantada por Loserth (de que Hus basicamente copiava as ideias de Wycli$\mathrm{ff}$ ) e seu sucesso historiográfico, bem como os principais nomes da historiografia em língua inglesa (FUDGE, 2016, p. 100)

Spinka é o autor que impactou de modo mais profundo a historiografia, em língua inglesa, oferecendo, nos anos de 1960-70, os trabalhos mais aprofundados, com maior acesso a fontes e trazendo a tradução de diversos textos de Hus para o inglês. Algumas de suas principais posições, conforme Fudge, são:

Ele refutou a conexão Wyclifista, preferindo, ao contrário, argumentar que Hus herdou um impulso reformista nativo tcheco e chegou ao ponto de acusar Loserth de deliberadamente deformar e torcer os fatos [...] No modelo interpretativo de Spinka, Hus era o precursor que representava um estado de transição entre a Idade Média e a Reforma. (FUDGE, 2016, p. 125, tradução nossa) $)^{5}$

A posição antiga de Loserth ainda se mantém nas leituras menos aprofundadas de Hus. O extenso trabalho de Spinka compõe, de algum modo, a interpretação vigente na produção em língua inglesa. Há autores mais recentes oferecendo leituras que, de alguma maneira, trazem novas questões para o debate historiográfico, sendo o trabalho do próprio Fudge um dos mais significativos:

5 No original: “He refuted the Wyclifite connection, preferring instead to argue that Hus inherited a native Czech reform impulse and went as far as to accuse Loserth of deliberately warping and twisting facts. (...) In Spinka's interpretive model, Hus was a forerunner who represented a transitional stage between the Middle Ages and the Reformation." 
Sua monografia sobre o julgamento conclui que Hus obteve o que merecia e que o processo não foi ilegal nem processualmente irregular. Também vale a pena destacar que a personalidade e a ingenuidade política de Hus são examinadas e substituem a hagiografia do reformador. Contra Spinka e muitos outros, Fudge opõe-se à noção de que Hus era um protoprotestante, um João Batista medieval tardio a preparar 0 caminho do Senhor para o divinamente inspirado Martinho Lutero. Fudge prefere ver Hus como um reformador católico tardio medieval, melhor compreendido sem a referência às reformas europeias do século XVI. (FUDGE, 2016, p. 132, tradução nossa). ${ }^{6}$

Estes são os principais debates a respeito de Hus, dentro dos quais nos inserimos. Para escrevermos este artigo, trabalhamos com um recorte de sete documentos dentre os 107 que compõem a epistolografia de Hus, disponivel hoje e traduzida em língua inglesa. A edição mais completa é a de Spinka (1972), que traduziu as cartas a partir da compilação feita por Novotný (1920). É a partir da tradução de Spinka (1972), que fizemos as versões em português, apresentadas neste artigo, e as cartas por nós selecionadas, nessa edição, são numeradas de 45 a 52 .

Reunimos, aqui, novas reflexões e elementos que apresentamos em pesquisas anteriores. Em nosso estudo mais abrangente sobre a correspondência hussita, já fizemos menções a cinco dos sete documentos aqui

6 No original: "His monograph on the trial concludes that Hus got what he deserved and that the process was neither illegal nor procedurally irregular. It is also worth noting that Hus's personality and political naiveté are scrutinized and replace the hagiography of the reformer. Against Spinka and numerous others, Fudge demurs at the notion that Hus was a Proto-Protestant, a late medieval John Baptist preparing the way of the Lord for the divinely inspired Martin Luther. Fudge prefers to see Hus as a late medieval Catholic reformer best understood without reference to the European Reformations of the sixteenth century." Destaque para o fato que Fudge analisa sua própria produção no estado da arte que apresentou e todas as menções a seus próprios escritos são feitas em terceira pessoa. selecionados $(45,46,48,50$ e 51), apresentando, em linhas gerais, a descrição da viagem (AGUIAR, 2012, p. 180 e seguintes). As questões referentes ao conflito entre tchecos e alemães já apresentamos em artigo recente (AGUIAR; SILVA, 2015). O caráter de testamento da carta de número 45 já esteve presente em (2011a, texto que foi incluído na publicação de 2012). o caráter original do texto que aqui escrevemos se encontra no exercício de uma nova leitura do conjunto de cartas selecionado, buscando, desta vez, não a narrativa da viagem (como fizemos em 2012), mas os elementos que nos permitam compreender a construção das imagens de si e do outro, conforme apontamos acima.

Os referenciais teórico-metodológicos que subsidiam nossa leitura são os conceitos de paradigma indiciário, distância, estranhamento, perspectiva e narrativa histórica, a partir dos textos de Ginzburg (1989; 2001; 2006), estudos sobre cartas, em especial Bastos; Cunha; Mignot (2002), Galvão; Gotlib (2000), Tin (2005) e estudos sobre histórias de vida, em especial a partir do livro de Nóvoa; Finger (2010). Sobre Hus e seu contexto histórico, as pesquisas de Spinka (1968) são nossos principais referenciais.

\section{Quando o eu já está morto}

No início de outubro de 1414, quando estava em exílio na cidade de Krakovec, Hus escreve uma carta para Martin de Volyně, seu discípulo. A datação desta carta não é precisa, mas está claro para os editores da correspondência hussita que se trata de um texto escrito às vésperas do início da viagem para Constança. Trata-se de uma carta com uma característica singular, em relação a todas as outras disponíveis para nós. Ela estava lacrada e dispunha de instruções para ser aberta apenas caso se obtivessem notícias seguras da morte de quem a escreveu. 
Esta carta consiste, portanto, de um texto escrito como testamento, ${ }^{7}$ como últimas palavras, uma carta de despedida (ver AGUIAR, 2011b). Hus escreve-a pensando que estas seriam as últimas palavras que estaria dirigindo a Martin. Escreve como alguém que já está morto, alguém que não tem mais como voltar e ensinar a seu discípulo como viver. É por isso que se trata de um texto carregado de marcas de um tempo futuro, que busca relembrar o passado ou levantar possíveis ações futuras, o que podemos observar em alguns trechos da carta:

Lembre-se que desde sua juventude eu the ensinei a servir a Cristo Jesus e se tivesse sido possivel teria gostado de te ensinar em um único dia tudo aquilo que eu sabia. [...] Mas se você se tornar um pastor, cuidado ao ter uma jovem mulher como cozinheira [...] Eu também temo que, se você não corrigir sua vida desistindo de vestimentas suntuosas e supérfluas, você será severamente repreendido pelo Senhor; [...] Adeus, em Cristo Jesus [...]. (SPINKA, 1972, p. 121, grifos nossos)

O texto possui, ainda, uma estrutura menos rígida dentro das regras formais de escrita de cartas na época. Como vemos em Tin (2005, p. 37 e seguintes), os códigos da retórica da escrita de cartas, desenvolvidos no período tradicionalmente denominado de Baixa Idade Média, propõem que elas contenham, basicamente, cinco partes: saudação, captação da benevolência, narração, petição e conclusão. Como demonstramos (AGUIAR, 2012, p. 79 e seguintes), as cartas de Hus, em geral, seguem esses códigos. Mas essa carta a Martin consiste, basicamente, de uma lista de pedidos (de últimos pedidos). Em síntese, ele pede a seu discípulo que tome cuidado com as mulheres (pedido

7 Já escrevemos a respeito desta carta (AGUIAR 2011a, retomado em 2012), visto tratar-se de um importante documento para registrar o modo como Hus transmite seu legado a seus discípulos. Aqui, contudo, nossa preocupação está na maneira como o remetente constrói sua autoimagem, às vésperas da viagem para Constança. feito duas vezes no texto), com a avareza e o luxo, com coisas levianas (como jogar xadrez). Há ainda uma distribuição de bens: sua túnica cinza, sua túnica branca e algumas moedas.

É digno de nota que a carta, como uma escrita de si, possui as marcas da implicação do sujeito na sua narrativa. O sujeito projeta uma imagem de si que o pesquisador pode captar quando "invade" o pacto do afeto entre missivistas (LIMA; FIGUEIREDO JÚNIOR, 2000, p. 244, retomado por MIGNOT, 2002, p. 116). Neste texto, visto ser uma carta-testamento, carta de despedida, o autor faz escolhas sobre o que é mais relevante escrever e essas escolhas se potencializam visto não haver mais futuro possivel para uma nova escrita. Esse não futuro possivel aumenta a relevância do ato de escolher e deixar marcado o que importa mais.

A questão do cuidado com as mulheres e com os jogos é um excelente exemplo de como nesta escrita de si podemos observar o indivíduo como "reapropriação singular do universal social e histórico que o rodeia" (FERRAROTTI, 2010, p. 45), na medida em que ele se apropria de códigos sociais de conduta como seus e os transmite a seu discípulo. Hus mostra, nesta carta, o modo como concebia o jogo como uma diversão possível, em sua juventude e, depois, apropriando-se de uma nova regra social, passou a considerá-lo errado (condenação feita também em outras duas cartas, de números 3 e 20 da coleção de Spinka). Aquilo que era aceitável para um jovem passou a ser equivocado, no momento em que ele se tornou um clérigo, assumindo novo papel social e seguido as regras desse novo papel.

Hus segue as principais tipologias medievais em relação à mulher e ao jogo. Mulheres são perigosas, pois, assim como Eva, elas levam o homem a se perder. Como nos mostram Le Goff e Schmitt (2006), em referência à força do caráter binário (masculino/feminino) do gênero, na Idade Média: 
Os religiosos que viviam a recusa da carne e a distância das mulheres retiveram deste catálogo binário sobretudo a negatividade do pólo feminino, com o qual eles alimentaram sua própria visão misógina da feminilidade. Eles podem assim aumentar o inventário dos defeitos e dos problemas ligados às mulheres. As piores invectivas contra a mulher, assimilada ao seu corpo, condenada por tudo o que é ligado a ele, surgem no fundo dos claustros onde se renunciou aos sentidos e ao mundo. (LE GOFF; SCHMITT, 2006, p. 144-145)

Igualmente, os jogos são perigosos, pois eles despertam sentimentos e emoções fortes demais, afastando-se da virtude. Eles são, para os clérigos, uma "encarnação do mal":

Os jogos são perda de tempo, dom divino por excelência, atividades geradoras de distúrbios morais e sociais diversos, eles afastam de Deus e dos labores que se fazem ao serviço do próximo. Já que se revela impossivel extirpá-los, convém controlá-lo e limitar seu uso [...] Esse discurso global da Igreja, cuja argumentação é bastante pobre, dificilmente convence em razão das fraquezas do próprio corpo eclesiástico face às seduções do jogo. (LE GOFF; SCHMITT, 2006, p. 34)

Outro elemento fortemente presente na carta a Martin é o caráter de intimidade entre os missivistas. Cartas podem criar redes de relacionamentos e afetos (MIGNOT, 2002) e a correspondência hussita constrói algumas dessas redes. Uma delas é a rede daqueles que são os mais próximos, os mais amigos, os discípulos mais importantes, os nobres que mais ajudaram. Há indícios, nesta carta, de marcas de intimidade. Indícios não são apenas elementos pequenos que escapam à primeira vista, mas elementos que se destacam justamente pelo caráter de estranhamento que eles causam, quando vistos em perspectiva. Perspectiva, aqui, entendida como uma metáfora cognitiva: "a tensão entre ponto de vista subjetivo e verdades objetivas e verificáveis" (GINZBURG, 2001, p. 197). Hus escreve desta maneira ape- nas nas cartas direcionadas a Martin e a outros destinatários mais próximos e, nesta carta em especial, essas marcas se destacam, visto se tratar de um texto que, como apontamos, segue menos as regras formais da retórica medieval. Dois são os principais trechos em que esses indícios aparecem.

No primeiro trecho, Hus aponta para seus erros de juventude, utilizando-os como exemplos que não devem ser seguidos:

Você sabe que, ai de mim, antes de eu me tornar um clérigo, eu gostava de jogar xadrez e o fazia com frequência. Desperdicei meu tempo, e por causa desse jogo provoquei, com tristeza e por diversas vezes, a cólera em mim e nos outros. Consequentemente, por causa também de inúmeras outras faltas que eu cometi... (SPINKA, 1972, p. 121, grifos nossos)

Não é incomum olhar para si mesmo sob o topos do pecador em penitência, nesse período da história, especialmente para quem estava escrevendo de si como alguém que "já estava" morto. Mas há mais do que apenas uma confissão, há uma confissão marcada por expressões de intimidade e intensificação do sentimento.

O segundo trecho encontra-se na despedida da carta, na qual, durante a distribuição de seus bens, Hus afirma saber que Martin detesta cinza: "Você pode ficar com a túnica cinza, se você quiser, como uma recordação; mas como eu acredito que você detesta cinza, dê, portanto, para qualquer pessoa que the parecer meIhor" (SPINKA, 1972, p. 121, grifos nossos).

É claro que, isolados, estes elementos não são suficientes para indicar a intimidade. Mas na composição destes elementos com o caráter menos formal da escrita, com a expressão de um eu "morto" e com as diferenças em relação às outras cartas da epistolografia hussita, eles se constroem como marcas de uma relação específica, no caso, de mestre-discípulo. ${ }^{8}$

8 Não podemos deixar de apontar que há outros elementos presentes em outras cartas a Martin (ou que 
Nesta carta, encontramos o Si como morto e como mestre. E quem é o outro? Como carta final, a escolha de conselhos e exortações para que tome cuidado constrói uma imagem de um outro que está diante de uma responsabilidade. Martin recebe, aqui, um legado que deverá assumir, do exemplo de Hus. O mestre deixa seu exemplo para que o discípulo assuma seu lugar. A carta está carregada de expressões que marcam a preocupação do mestre de que o outro precisa seguir seus conselhos, pois poderá se perder se fizer o contrário (lembremonos do exemplo do xadrez na juventude!). São palavras como "exorto-lhe" a seguir os mandamentos, "lembre-se que, desde a juventude, eu lhe ensinei a servir ao Cristo...", "você sabe que eu denunciei...", "eu imploro que você não seja ganancioso", entre outras. O outro é alguém que conhece Hus, há bastante tempo, e sabe o que tem que fazer: "Já que você conheceu bem minha pregação e minha conduta em público desde sua juventude, não considero necessário escrever-lhe mais sobre isso" (SPINKA, 1972, p. 120-121).

São imagens relacionadas. Hus torna-se o mestre que deixa seu legado após a morte para aquele discípulo que terá que continuar sem a sua presença, assumindo, assim, novas responsabilidades.

\section{Em luta, em perigo e em sofrimento}

Em 19 de outubro de 1414, no oitavo dia da viagem para Constança, Hus escreve uma carta pastoral $^{9}$ na qual anuncia que irá ao concílio.

o mencionam), que corroboram para aumentar nossa convicção desse caráter intimista da carta, elementos esses que apresentamos em outras oportunidades (ver Aguiar, 2011a, incluído em 2012, p. 214 e seguintes).

9 Termo que assumimos para cerca de um quarto da correspondência hussita, a partir da definição de Freitas (2002, p. 61-62), na qual o destinatário é suposto "mais como um ouvinte do que como um leitor", um ouvinte que é "imaginado em assembleia, o que quer dizer, em silêncio". Elegemos quatro características
O tom do anúncio é de denúncia. Ele afirma ter um registro de todos aqueles que falaram falsidades a seu respeito e que iria apontá-los se tivesse tido oportunidade para pregar antes da viagem.

Quis pregar-lhes antes de minha jornada, antes de minha partida para o Concílio de Constança e, em especial, informá-los a respeito dos falsos depoimentos e dos nomes das testemunhas que falaram contra mim. Eu tenho todos os seus nomes e os registros de seus depoimentos e os anunciarei a vocês para que, caso eles me difamem ou me condenem à morte, vocês, sabendo de tudo, não temam, como se eu tivesse sido condenado por alguma heresia por mim cometida. (SPINKA, 1972, p. 122, grifos nossos)

Mais abaixo, afirma que são justamente os tchecos os seus maiores inimigos e eles são muitos. Mas eles serão reconhecidos quando o concílio acabar.

Eu comecei agora o caminho sem um salvo-conduto, cercado de grandes e numerosos inimigos - entre os quais os piores são meus compatriotas, como vocês perceberão dos testemunhos e aprenderão após a conclusão do Concílio. Pois haverá muito mais deles contra mim do que houve de bispos, mestres, príncipes seculares e juristas contra nosso misericordioso Redentor. (SPINKA, 1972, p. 122-123, grifos nossos)

Como a realidade é descontínua, micro e macro-história não se explicam mutuamente, mas se relacionam como duas formas de levantar perguntas sobre determinado contexto que permita construir uma narrativa histórica (GINZBURG, 2006, p. 269). Assim sendo, a "explicação" dos sentidos de algumas das palavras aqui destacadas nas cartas de Hus, não são a projeção do macro no micro. Sua vida e suas escolhas não são explicadas pelos eventos aos quais ela se refere, dada a complexi-

para as cartas pastorais de Hus: elas foram escritas do exílio, o destinatário é um sujeito coletivo, elas foram escritas em vernáculo e servem para compensar sua ausência aos sermões, na Capela de Belém. A descrição dessas características bem como suas nuanças estão em Aguiar (2012, p. 167) 
dade dos motivos das ações de um indivíduo. É o caso de sua viagem sem o salvo-conduto e da declaração que seus inimigos estão entre os tchecos. Sobre esta última, reservaremos um espaço posterior deste artigo para discutir (dado que outros elementos estarão presentes nas cartas seguintes). Mas sobre o salvo-conduto, que será quase como um leitmotiv das cartas da viagem, podemos fazer um exercício de alternância entre macro e micro.

Venceslau IV (Václav IV) era rei da Boêmia e foi imperador do Sacro Império Romano-Germânico (1378-1400), assim como seu pai, Carlos IV (Karel IV, imperador entre 1349-1478). Seu irmão Sigismundo (Zikimund) era rei da Hungria e viria a assumir o Império posteriormente (1433-1437). A relação de Hus com Venceslau era razoavelmente boa, a se considerar que o clérigo era confessor da rainha e recebera apoio do rei em diversos momentos, ao longo da primeira década do século XV.

Desde o ano de 1378, a Cristandade ocidental enfrentava o Cisma Papal. Dois papas, um de Avignon e outro de Roma, disputavam a legitimidade de sua eleição e dividiam os reinos europeus em grupos divergentes de apoio. A cada morte de um dos papas e eleição do seguinte, as tentativas de se resolver o conflito não surtiam efeito. Tanto no âmbito teológico quanto no âmbito político, diversos sujeitos tentaram capitanear a resolução do cisma e Venceslau, que estava perdendo apoio político, encontrou na convocação de um novo concílio, em 1409, a estratégia para reverter essa situação. Como parte da negociação para obter apoio dos professores tchecos da Universidade de Praga, o então imperador emite um decreto (Decreto de Kutná Hora), que, na prática, nacionaliza a Universidade, dando maior poder de decisão aos tchecos e levando os professores alemães a deixarem Praga, em represália, para fundarem outra universidade. Hus torna-se, então, reitor da universidade tcheca, o que é outro in- dício do bom relacionamento com Venceslau. ${ }^{10}$

Esse bom relacionamento só é abalado pelo posicionamento contrário de Hus à venda de indulgências, no ano de 1411, que, após a bula papal de 9 de setembro desse ano, financiariam uma cruzada contra o rei Ladislau, de Nápoles (SPINKA, 1968, p. 132 e seguintes). Hus, ao se posicionar contra a bula papal, perde o apoio de Venceslau, como perde quase todos os apoios políticos que possuía até então. Quando houve a segunda excomunhão, acompanhada do interdito, em 1412, Venceslau incentivou Hus a seguir para o exílio.

No entanto, no que diz respeito às relações políticas do rei e ao cisma papal, Venceslau acabou derrotado visto que o Concílio de Pisa de 1409 não apenas não resolveu o conflito entre os dois papas como acabou por piorá-lo, ao instituir um terceiro papa que não conseguiu reunir em seu entorno a cristandade. Sigismundo busca consolidar apoio político para si. É ele quem convoca o Concílio de Constança, buscando uma cidade longe o suficiente dos principais pontos de apoio de cada papa, para evitar que houvesse um número desproporcional de cardeais de uma região em relação à outra. Resolver o cisma seria uma ação que lhe traria poder e prestígio, e foi o que ele reuniu nesse processo.

Venceslau sugeriu a Hus que fosse ao concílio, pois lá poderia defender-se das acusações que sofria. Sigismundo disponibilizou alguns nobres cavaleiros para compor a comitiva da viagem, de modo a protegê-lo, e the prometeu um salvo-conduto. Esse salvo-conduto nunca veio e, ao final da viagem, Hus acabou preso. Ao longo do concílio, os companheiros de Hus descobriram que Sigismundo, de fato, nunca quis dar o salvo-conduto e, de certo modo, esta promessa foi um recurso para conseguir que o clérigo fosse preso em Cons-

10 Sobre a questão das identidades tcheca e alemã e a nacionalização da Universidade de Praga, já escrevemos em Aguiar; Silva (2015). 
tança. Quando a notícia desse estratagema se espalhou na Boêmia, a oposição a Sigismundo cresceu fortemente, piorando com a morte de Hus, em 1415. Na prática, ele nunca conseguiu recuperar o apoio político dos tchecos e, até os dias de hoje, ele ficou presente no imaginário tcheco como o "raposa vermelha" (ele tinha cabelos ruivos).

Avançamos temporalmente para além do escopo da narrativa da viagem que aqui estamos tratando justamente para, de volta ao contexto desta carta (e das próximas), darmos novo sentido às palavras de Hus. Aqui, quando ele afirma viajar sem um salvo-conduto, estão presentes o incentivo de Venceslau, o apoio dos cavaleiros de Sigismundo e uma promessa. Ao longo das cartas de viagem, Hus fará diversas menções às suas tentativas de obter o documento e o fato de fazer toda a viagem sem esse documento e nada de mal acontecer impactará na imagem que faz de si e dos outros.

Enquanto na carta a Martin, Hus é o morto, aqui, na carta a seus paroquianos, ele está cercado de inimigos, ele é alguém que luta, pois segue viagem apesar deles e tem certeza que, de alguma forma, os inimigos serão derrotados. Ao mesmo tempo em que está em luta, Hus está em sofrimento. A carta está carregada de imagens que remetem ao sofrimento do Cristo e à sua morte, tomando-os como modelo para o sofrimento que Hus está vivendo e a morte que espera encontrar. É o que encontramos em trechos como estes:

Vocês sabem que por muito tempo eu trabalhei fielmente entre vocês, pregando-lhes a Palavra de Deus, sem heresias ou erros, como vocês estão cientes, e que sua salvação foi, é agora e continuará a ser o meu desejo até a morte. [...] Mas eu confio em nosso misericordioso, sábio e poderoso Salvador que ele me dará, por causa de Sua promessa e por meio de nossa fiel oração, a sabedoria e a coragem do Espírito Santo para permanecer firme, de modo que eles não serão capazes de me desviar para o lado errado, mesmo que Ele me conceda sofrer tentação, desgraça, prisão ou morte; Ele Mesmo sofreu e permitiu a Seus mais queridos servos a sofrerem igualmente, oferecendo-nos assim um exemplo de que devemos sofrer por Sua causa e por nossa salvação. [...] Talvez vocês não me vejam em Praga antes de eu morrer [...]. (SPINKA, 1972, p. 122-123, grifos nossos)

Ao mesmo tempo em que esta carta é uma pregação, ela guarda uma característica muito comum da escrita epistolar: dada a distância, a escrita da carta serve para amenizar o sofrimento. Cartas, ao mesmo tempo em que mantêm "vínculos à distância", mostram-nos "a intensidade do relacionamento entre os missivistas" e "além de uma emoção, [são] uma forma de ousar, de ser transparente e vulnerável" com o destinatário (BASTOS; CUNHA; MIGNOT, 2002, p. 5-6). As diversas referências à morte colocam Hus no lugar de mártir. A imagem do mártir está associada a uma confiança e é por isso que ele se apresenta em luta. Ao fazê-lo, cria aqui três imagens dos outros. Os primeiros são os destinatários da carta: eles são seus fiéis, que estão ouvindo a pregação, são frágeis e precisam de suas palavras para permanecerem firmes. Seu exemplo de firmeza é o exemplo que eles precisam para dar conta de compreender o que está acontecendo. Eles precisam de cuidados e precisam permanecer fortes, pois a morte pode afastá-los mais do que a distância que a carta consegue compensar.

Os segundos são justamente os inimigos, que não são nomeados, mas são nomeáveis e serão expostos quando a verdade vier à tona. Além disso, estão por perto, são compatriotas, são pessoas que podem estar ao lado. É por isso que Hus é tão incisivo em sua carta para que seus fiéis "não temam". Além disso, há também um terceiro outro que não está explicitamente presente na carta: Sigismundo. É aquele que está no plano de fundo de toda a 
carta, aquele que prometeu o salvo-conduto e cuja promessa será confirmada (ou não) na viagem que se inicia.

Ainda no âmbito da imagem de alguém em luta, encontra-se outro documento presente na correspondência hussita. De número 47, na coleção de Spinka, datado apenas de "outubro de 1414 ", trata-se de uma nota pública exposta pela comitiva de Hus durante a viagem. Não se trata de uma carta propriamente dita, mas exerce a função de carta pública. Já em Nuremberg, nas terras germânicas, Hus e sua comitiva penduraram cartazes pedindo que as pessoas o liberassem para continuar sua viagem a Constança. Ele afirma que, assim como esteve à disposição para afirmar sua profissão de fé diante do sínodo do arcebispado de Praga, ele também está disposto a fazê-lo diante do Concílio. Pede, portanto, se alguém quiser acusá-lo de heresia, que o deixe seguir para Constança, onde ele poderá se posicionar. $\mathrm{Pa}$ rece-nos que Hus, como está viajando sem um salvo-conduto, espera, de algum modo, poder contar com a compreensão de seus inimigos para que ele não seja interrompido em sua viagem. Ele está em perigo e os outros que encontrará na viagem são inimigos.

\section{Quando os outros não são os inimigos esperados}

Em 20 de outubro de 1414, Hus escreve uma carta na qual relata sua viagem. De todas as cartas referentes à viagem, esta é a mais narrativa. Ele conta que passou pelas cidades de Bärnau, Neustadt, Weiden, Sulzbach, Hersbruck e Lauff, sendo bem recebido em todas. Os clérigos estão interessados em conversar com ele e as pessoas reúnem-se para conhecê-lo. A descrição de sua passagem por Nuremberg é um ótimo exemplo do tom da carta:

E ei! Chegamos a Nuremberg, onde os mercadores que nos precederam haviam anunciado nossa chegada. Por esse motivo, o povo estava parado nas ruas, olhando em volta e perguntando qual era o Mestre Hus. Antes do jantar, o Mestre Johann Helwel, pastor de St. Laurence, me enviou uma carta escrevendo que há muito tempo ele desejava falar comigo abertamente. Eu the respondi na mesma carta que ele deveria vir. E ele veio. Como eu já havia escrito um aviso [convidando para entrevistas], desejando publicá-lo, o Lord Wenceslas [de Dubá] ao mesmo tempo me enviou a informação de que os cidadãos e mestres estavam reunidos e desejavam me ver para conversar comigo. Levanteime imediatamente da mesa e saí. Os mestres me mandaram dizer que deveríamos conversar privadamente. Eu lhes disse: 'Prego em público e desejo que todos os que quiserem possam me ouvir'. A partir daquela hora, conversamos diante dos conselheiros e cidadãos até o anoitecer. (SPINKA, 1972, p. 125-126, grifos nossos)

Este trecho oferece-nos inúmeros elementos para compreendermos a viagem de Hus, mas, se não realizarmos uma leitura de estranhamento do óbvio (GINZBURG, 2001, p. 41), não conseguimos observá-los claramente. A distância temporal que nos separa de suas cartas pode fazer com que não compreendamos que esses deslocamentos entre cidades levavam dias, feitos a cavalo, em comitiva. Parar numa cidade para comer e descansar é quase que obrigatório. Portanto, a expectativa de como ele seria recebido na cidade é sempre grande. Os mercadores que percorrem as rotas terrestres fazem parte de um crescente movimento de melhorias nos deslocamentos por estradas, que aumenta desde o século XII, se consolidando com grande força já no século XIII (LE GOFF; SCHMITT, 2006, p. 192). Mas esses mercadores não levam apenas mercadorias e documentos comerciais; eles também levam informações, notícias, boatos. A notícia da chegada de Hus, um clérigo perseguido pela Igreja, acusado de defender ideias, no mínimo, diferentes, causaria (como causou) alvoroço na cidade. 
Numa época em que só se conhece o rosto de quem se vê,11 a identificação se dá por aclamação. É por isso que Hus afirma, logo no início da carta que, quando chegou a Sulzbach, diante dos conselheiros e anciãos, disse-lhes: "Olhem! Eu sou o Mestre Jan Hus, de quem, suponho, vocês ouviram muitas maldades. Questionem-me, à vontade" (SPINKA, 1972, p. 125). E é por esse mesmo motivo que as pessoas perguntavam: "qual daquelas pessoas era o tão falado Hus?"

Além disso, a carta que recebe de Johann Helwel expressa os códigos formais das relações entre intelectuais e a afirmação de Hus que respondera na mesma carta (por que ele precisava afirmar isso?) é mais um indício, dentre os diversos que estão presentes na carta, de que estava aberto a conversar e não eram necessárias tantas formalidades. Essa menção parece servir como destaque da velocidade com a qual Hus queria que a resposta chegasse. Escrever na mesma carta, aproveitar o mesmo suporte, aparece como uma forma de não perder tempo com a preparação formal da escrita. Não nos parece uma questão de falta de papel, tinta, pena etc., como estará mais explícito em outros trechos nas cartas da prisão. Ou ainda, Hus tenta mostrar na sua narrativa que não queria se esconder e que preferia falar abertamente (não precisaria ser reservadamente, como por uma carta), afinal ele "prega em público".

Há um esforço do missivista em destacar como foi bem recebido em todas as cidades e

11 Nesse caso, é icônica a história de Martin Guerre, narrada e analisada na obra de Natalie Zemon Davies. Um viajante que chegava a um vilarejo na região da Occitânia, em meados do século XVI, sendo confundido com um homem que havia deixado sua família anos antes, percebe aí uma oportunidade de se estabelecer e se apresenta para todos como Martin Guerre. Como muitos anos já haviam se passado desde que o Martin Guerre "original" tinha ido embora, o rosto do "impostor" era suficientemente parecido e as informações que ele conseguiu reunir a respeito do homem que ele assumiu o lugar bastaram para que ele pudesse viver alguns anos no lugar do desaparecido. Até que o "original" retornou. Ver Davis (1987). por todas as pessoas. Ele afirma isso reiteradamente e a escrita relata uma longa sequência de acontecimentos em poucas linhas. Sua intenção fica mais clara quando termina seu relato. Ele quer mostrar que seus inimigos não estavam entre os alemães. Os alemães aceitaram seu pedido de continuar a viagem e não impuseram o interdito sobre a cidade. Já é entre os tchecos que ele encontra seus inimigos.

Saibam que até agora eu não encontrei nenhum inimigo. [...] Todas as esposas dos hospedeiros e seus maridos receberam-me em todos os lugares com grande gentileza. Eles não impuseram o interdito em qualquer lugar. Todos elogiam minha nota escrita em alemão. Eu afirmo, portanto, que não há aqui maior inimigo do que entre os habitantes do reino da Boêmia. (SPINKA, 1972, p. 126, grifos nossos)

Esta é a narrativa central da carta e a principal imagem que Hus quer construir. Ele é alguém que tem força, coragem, está sempre aberto a falar livremente, em público. Os outros, alemães, recebem-no bem, são cordiais, dispostos a ouvir e a conversar sem preconcepções a respeito de Hus. Aqueles que eram os inimigos, na verdade, não o são. Os inimigos, está confirmado, são os tchecos - especialmente os tchecos.

Este é um elemento que se tornará muito forte, ao longo das cartas de Hus escritas da prisão. Em diversas cartas posteriores, ele enfatizará como, no Concílio, serão os tchecos os seus maiores perseguidores, "nossos inimigos mais ferozes"; que o Concílio condenou seus livros escritos em tcheco "sem nem ao menos os terem ouvido ou visto. E mesmo que os tivessem ouvido, não os teriam entendido", mas foram os tchecos, "os provocadores", que levaram à sua condenação (SPINKA, 1972, p. 167, 195, 196).

O convivio secular entre tchecos e alemães, geograficamente vizinhos, alternou momentos de intercâmbio cultural com conflitos marca- 
dos (SCALES, 1999, cujo argumento desenvolvemos em AGUIAR; SILVA, 2015, p. 313 e seguintes). Com o decreto de Kutná Hora, em 1409, essa relação tornou-se bastante conflituosa. Já havia divergências entre os professores tchecos e alemães, na Universidade de Praga, especialmente em relação a suas convicções filosóficas e teológicas. Entre os tchecos, realistas, e os alemães, nominalistas, houve grande debate a respeito da chegada dos textos de John Wycli$\mathrm{ff}$, nos primeiros anos do século XV. Wycliff era considerado um realista que oferecia fortes argumentos para sustentar as posições teológicas que os tchecos defendiam. Com a saída dos professores alemães, o debate permaneceu entre os tchecos.

De certo modo, esse autor causou furor entre alguns dos professores tchecos, inclusive Hus. No entanto, as ideias de Wycliff combatiam a hierarquia da Igreja e, no contexto do Cisma Papal, fortaleciam ideias de oposição a essa hierarquia. Como o arcebispo de Praga opôs-se às ideias desse intelectual inglês (o Concílio de Constança as condenaria posteriormente como heréticas), houve professores tchecos que se posicionaram a favor do arcebispo e contrários a Hus, que sustentou as posições de Wycliff. Mas a oposição mais forte ocorreu durante a querela da venda de indulgências. Foi nesse momento em que alguns professores tchecos se separaram daqueles que defendiam uma reforma da Igreja e iniciaram uma oposição direta à Hus. Esta oposição foi uma das mais importantes para sua posterior condenação pelo Concílio.

Quando afirmamos que separar inimigos de não-inimigos é o motivo central da carta, pautamo-nos não apenas no que está dito. Mas há uma marca da escrita que favorece essa nossa interpretação. Logo após ter feito as afirmações que citamos acima, Hus escreve: "E o que mais devo escrever?" (SPINKA, 1972, p. 126). Agora que já escreveu o que quis, mas ainda tem tempo e espaço, o que mais poderia escrever? Ter a possibilidade de escrever mais, quando tomada por oposição ao tempo corrido da escrita de outras das suas cartas, mostra o quanto neste momento da viagem ele está mais seguro de si e transmite uma imagem de que tudo está tranquilo. Ele constrói a imagem de alguém esperançoso para um destinatário que receberá bem essa notícia. Essa mudança de atitude está tão explícita que nos lembramos, analogamente, da frase do escritor norte -americano do século XX, famoso pela produção de romances policiais, Raymond Chandler que, preso ao gênero literário que escolheu trabalhar, viu nas cartas um espaço para se exprimir: "Suponho ter revelado nas cartas mais ou menos aquelas facetas da minha mente que tinham de ser escondidas ou distorcidas no que escrevi para publicação" (apud HALL, 2000, p. 72). Hus revelou bastante nesta pequena frase.

O final da carta é dedicado a apontar não mais o que ocorreu na viagem, mas como seguirão, nos próximos dias. Hus elogia seus companheiros de viagem. A comitiva seguirá direto para Constança e eles estão acompanhando os movimentos do rei Sigismundo e do papa João XXIII. Eles optam por seguir direto para Constança, local onde o papa está por chegar, por ser mais rápido do que ir ao encontro do rei para obter o salvo-conduto. Se ele foi tão bem recebido na viagem, talvez seja bem recebido em Constança.

\section{Na expectativa, mas em luta}

As três cartas seguintes foram escritas em Constança, sendo duas logo nos primeiros dias após a chegada. Elas tratam diretamente da viagem e propõem uma autoimagem de Hus como alguém que está lutando ao lado da verdade, foi bem recebido por todos e está esperançoso diante do Concílio. Diversos elementos da alternância entre macro e micro, bem 
como das características da escrita de cartas, voltam a aparecer aqui.

Na carta escrita em 4 de novembro de 1414, Hus faz um breve relato de como está sua estadia em Constança. Conta que chegaram sem contratempos à cidade e que está hospedado em uma rua próxima à residência papal. Aponta que o procurador papal expôs na igreja os processos "contra o excomungado e teimoso Jan Hus, suspeito de heresia", mas isso não o incomodava, pois "Deus o enviou para dizer coisas más contra mim por causa de meus pecados, como um julgamento que eu sei e estou disposto a sofrer um pouco por Seu nome" (SPINKA, 1972, p. 129-130, grifo nosso).

Esta é a única menção na carta a algum tipo de sofrimento - que é minimizado por Hus, como pudemos observar no destaque. Todo o resto da escrita é dedicado a notícias da preparação do Concílio (como as previsões de chegada do papa espanhol e do rei Sigismundo, ou a descrição do movimento de bispos e cardeais pela cidade), bem como de seus esforços para conseguir uma audiência com o rei e com o papa João XXIII (Hus declarou ter enviado emissários a ambos). A questão dos recursos para se manter em Constança aparece duas vezes na carta. Na primeira, ele comenta o alto custo da moradia, mas o baixo custo do transporte (a cavalo): “A comida é muito cara: uma cama custa meio florim por semana. Os cavalos são baratos: um custando seis sexagenae na Boêmia é comprado aqui por sete florins" (SPINKA, 1972, p. 130). Este comentário é seguido de um pedido de ajuda com recursos que em breve necessitará: “Eu acho que logo terei necessidades. No que diz respeito a elas, peça ajuda aos amigos cujos nomes seria muito demorado citar e oneroso para me lembrar de memória" (SPINKA, 1972, p. 130).

Mais à frente, após comentar sobre os cavalos dos cardeais, Hus lamenta os gastos que muitos de seus amigos precisaram fazer durante a viagem para que ele pudesse estar lá e que não poderá ajudar. Ele justifica que ainda precisa de seu cavalo e por isso não pode cedê-lo. Nesta carta, ele constrói uma imagem de alguém que está bem, em busca de ser ouvido e admirado com a movimentação da cidade. É muito ajudado e muito bem recebido. Seus inimigos não o incomodam.

Dois dias depois, sua carta é mais preocupada. Hus já inicia o texto pedindo ajuda para manter-se firme, pois "muitos e poderosos adversários se levantaram contra mim". E, após listar alguns desses adversários, afirma não temê-los, pois “depois da grande batalha, haverá uma grande vitória e depois uma recompensa ainda maior e maior perturbação dos perseguidores" (SPINKA, 1972, p. 131-132).

É notável a diferença do tom entre estes inimigos e os apresentados dois dias antes. 0 que antes apenas "não o incomodava", agora se trata de uma "grande batalha". Um dos elementos que mais se destacam no trecho em que aponta essa batalha é justamente a indiferença do papa, que não quer se intrometer nesses processos, visto que são os próprios tchecos que estão perseguindo Hus. Diz o papa, de acordo com a narrativa da carta: "O que eu posso fazer? Afinal de contas, seus compatriotas o estão fazendo!" (SPINKA, 1972, p. 132).

Hus ainda espera conseguir uma audiência pública com o apoio do Rei Sigismundo e aguarda por sua chegada. O salvo-conduto é mencionado mais de uma vez nesta carta (assim como foi uma vez na carta anterior). Este é um elemento importante, como apontamos anteriormente, pois marca tanto a confiança de Hus na viagem (conseguiu viajar mesmo sem o salvo-conduto) quanto sua esperança de que poderia ser ouvido. Essa repetição também pode levantar uma autoimagem de força em relação ao contexto. Ele estava lá porque era forte o suficiente para enfrentar os 
desafios sozinho e o rei, quando chegasse, iria convalidar essa força.

Enquanto a narrativa de Hus a respeito do papa e do rei parecem apenas elementos de sua estadia em Constança, no nível macro, estes dois sujeitos estão cada um diante de um desafio. O papa João XXIII (papa de Pisa) abre o Concílio e espera ser reconhecido como o papa oficial. Os outros papas estão chegando. Chegar e abrir o Concílio era uma estratégia para tentar obter o apoio que estava perdendo (e, de fato, perderá, pois será condenado e preso poucos meses depois). Para Sigismundo, como apontamos antes, esse Concílio era sua oportunidade de agregar poder político. Hus era um elemento pequeno, mas importante da ação de ambos. Aqui, ele estava esperançoso de poder ter uma audiência. Mas, como ficaria claro no desenvolvimento das ações nas semanas seguintes, nem o rei nem o papa estavam dispostos a deixar que o clérigo tcheco falasse.

Outro importante relato da viagem é o tom sarcástico com o qual se refere a um de seus perseguidores: um "arauto". Hus relata que um bispo da cidade tcheca de Lebus o antecedia nas cidades anunciando que ele chegaria acorrentado e que as pessoas tomassem cuidado, pois ele era um leitor de mentes. Mas, ao invés das pessoas fugirem, elas se aproximavam mais e o adversário fez as pessoas "ouvirem a verdade". Hus está confiante: "Nós fomos tratados bem e honradamente em todas as cidades..." (SPINKA, 1972, p. 132).

Termina a carta novamente preocupado com suas necessidades materiais, mas é mais explícito desta vez, pedindo que os amigos contribuam: "Acho que em breve terei necessidades, se o Concílio se prolongar. Portanto, pergunte a quem quer que você conheça de meus amigos para uma contribuição, mas peça, a princípio, condicionalmente" (SPINKA, 1972, p. 132). Em suma, Hus apresenta uma imagem de alguém preocupado, com neces- sidades, perseguido, mas ainda está um tanto esperançoso. Há entre os outros aqueles que são grandes inimigos e aqueles que são tolos "arautos".

Por fim, dez dias depois, Hus escreve a última carta ainda em liberdade. Trata-se de uma carta pastoral, seguindo as características de diversas cartas semelhantes, anteriores. 0 texto segue a formalidade dessas cartas, indicando que foi escrito com o tempo e o cuidado necessários. Hus faz menções a seu sofrimento, mas numa perspectiva mais escatológica (na relação com o Anticristo, o Dia do Julgamento, o sofrimento do Cristo etc.) e menos em relação a sofrimentos específicos (sejam acusações, sejam necessidades). Sua menção à viagem e à sua estadia em Constança é breve, mas relevante, na medida em que sintetiza os principais temas tratados nas outras cartas: viagem tranquila, tchecos como inimigos e confiança em sua força. Os três elementos aparecem reunidos, conforme nossos destaques, no seguinte trecho, que começa falando de Deus:

Ele já me trouxe para Constance sem qualquer obstáculo. Em toda a viagem, andando abertamente como um clérigo e anunciando-me em voz alta ao povo, não encontrei nenhum inimigo aberto em nenhuma das cidades. Nem eu teria muitos deles em Constança, se o clero tcheco, que anda por aí implorando por benefícios, [em escravidão à] avareza, não tivesse desviado as pessoas. (SPINKA, 1972, p. 134, grifos nossos)

Mas a imagem de si como alguém que está forte diante de uma situação que ele enxerga como favorável é reforçada pelo descumprimento do interdito. Em um tom que pode chegar a ser sarcástico, Hus comenta que nunca deixaram de realizar os serviços religiosos em sua presença - nem mesmo o papa, que rezou a missa de abertura do Concílio, mesmo com Hus na cidade: "Vocês devem saber que em nenhum lugar os serviços foram interrompidos 
por minha causa, nem mesmo em Constança, onde o próprio papa realizou um serviço enquanto eu estava lá" (SPINKA, 1972, p. 134).

Seja por questionar a validade do interdito, seja por mostrá-lo como irrelevante (o próprio papa o estava desconsiderando), seja por mostrar sua força, Hus constrói uma imagem de alguém que está mais confiante e possui uma expectativa positiva diante do que viria a acontecer. Diversos são os outros destas últimas cartas. Temos tanto o rei e o papa, apresentados numa posição ainda pequena em relação à importância da narrativa da viagem. Vemos os inimigos, parte do clero tcheco, que são justamente os opositores mais ferrenhos. Vemos os outrora considerados inimigos, os alemães, que se não fossem os verdadeiros inimigos, estariam ao seu lado. Temos os destinatários das cartas, que precisam saber a verdade, para estarem atentos aos inimigos que estão tão perto.

São estas as imagens ao final da viagem. Daqui poderíamos partir para nossas análises finais. No entanto, mesmo que brevemente, devemos levantar considerações a respeito da carta de número 49, que propositalmente deixamos de lado em nossa reflexão até aqui.

\section{Algo de estranho no meio}

No meio da seleção de cartas que fizemos, há uma escrita no início de novembro de 1414. 0 destinatário é desconhecido bem como sua exata datação. Os editores colocam-na em Constança, portanto, após o término da viagem. Trata-se de uma lista de recomendações a um "querido irmão", portanto um clérigo. Spinka supõe ser Martin de Volyně, enquanto Novotný supõe ser Havlík (clérigo que o substituiu na Capela de Belém) (ver nota em SPINKA, 1972, p. 128). Não temos elementos para afirmar, com certeza, o destinatário, embora percebamos se tratar de alguém a quem Hus considera de algum modo subordinado, seja como discípulo, seja como seguidor, visto a retórica da escrita da carta não possuir nenhum cuidado considerável para alguém superior. 0 tom é mais direto e guarda menos elementos de intimidade do que a carta a Martin.

Não há nenhuma menção à viagem e Hus não menciona nada a respeito de si próprio. Para o conjunto da epistolografia hussita disponivel, trata-se de um importante documento para se debater. No contexto deste artigo, levantamos apenas duas questões. A primeira é: por que não comentar a viagem? Se for esta uma carta a Martin, ele poderia estar reescrevendo sua carta-testamento, de forma mais simples, retomando os principais conselhos. Se for a Havlík, justamente a pessoa que lia suas cartas pastorais em púlpito, não há motivos aparentes para não comentar a viagem.

A segunda pergunta é: por que não comentar nada a seu respeito? 0 texto inteiro consiste numa lista de conselhos, carregada de verbos no imperativo. Talvez esta carta tenha sido escrita de modo mais apressado. Estaria Hus preocupado com Martin, que, como não teria aberto sua carta anterior, talvez precisasse urgentemente de alguns conselhos? Estaria Hus em uma situação de perigo e, portanto, precisava escrever logo?

Trabalhar com cartas é lidar com fragmentos. A depender do momento em que esta carta tenha sido escrita em relação às três últimas comentadas acima ( 4 de novembro, 6 de novembro e 16 de novembro), nosso argumento de que Hus construiu uma imagem de si como alguém forte e em luta precisa ser matizado. Talvez sua confiança não seja tão grande assim. Ou, talvez, estejamos apenas diante de um texto de aconselhamento, prática comum nas cartas hussitas, que pode ter sido escrito rapidamente por algum motivo simples do cotidiano.

Neste momento, podemos apenas nos manter no âmbito da conjectura, na busca por 
outras fontes que nos permitam aprofundar a compreensão deste documento. Sustentamos nossa narrativa e argumentação a respeito das imagens que Hus faz de si, como toda verdade histórica, sujeita a novos documentos e novas possibilidades de leitura.

\section{Quando a viagem acaba (à guisa de uma conclusão)}

De uma carta de despedida diante da expectativa da morte a uma carta indicando força, pudemos observar o quanto a imagem que Hus constrói de si mesmo se modificou nesta viagem. Tendo passado cerca de dois anos em exílio, escrevendo e planejando formas de se defender, a viagem para Constança foi transformadora, na medida em que Hus se mostrou mais confiante e forte. Bons auspícios o acompanharam e os diversos trechos sarcásticos apontam para um sujeito seguro de conseguir vencer os inimigos, visto que foram muitas as pessoas que o ouviram com atenção. Se as pessoas puderam ouvi-lo na viagem, ele talvez pudesse ser bem recebido e ouvido no Concílio.

Não cabe aqui tratar das inúmeras mudanças na escrita e nessa imagem a partir do momento em que Hus foi preso. Sua última carta, dentre as que selecionamos para este artigo, foi escrita em 16 de novembro e Hus foi encarcerado em 28 de novembro de 1414. Daí em diante, as cerca de cinquenta cartas que dispomos foram escritas nessa condição, num período de quase oito meses até sua morte na fogueira. Há de se considerar, apenas como exemplo de como sua imagem se transforma amplamente, que a primeira carta escrita da prisão é curta, apresenta preocupação por falta de notícias dos seus, traz um pedido para que ele seja libertado e afirma que estava muito doente.

Com relação aos outros, a principal transformação deu-se na leitura que fazia a respeito dos alemães. Estes, sim, deixaram de ser inimigos, para ser pessoas abertas a conversar. Isso fortaleceu a imagem de que seus adversários tchecos eram, de fato, os principais inimigos. Os destinatários estiveram, em todas as cartas, retratados numa posição passiva: eles tinham que ouvir notícias, receber conselhos, acolher informações que thes oferecessem uma melhor compreensão do que estava acontecendo.

Pensando o sujeito como um "universal singular" (FERRAROTTI, 2010, p. 51), estas cartas podem oferecer uma leitura, que para além da própria transformação da imagem de si, permite compreender as condições macro que estavam presentes e nela estão expressas. Olhar para uma escrita de si, exige que nos deparemos com elementos diversos que nos permitam compreender como uma pessoa se torna quem ela é. Nas palavras de Dominicé:

São as interações, as articulações, os equilíbrios, enquanto estabilidade provisória de um conjunto, que vão indicar-nos pistas de reflexão e sugerir-nos hipóteses quanto à maneira como se desenha, ao sabor de um dado percurso de vida, aquilo em que cada um se torna. (DOMINICÉ, 2010, p. 195)

São inúmeras as possibilidades de leitura (escrita de cartas, viagens, condições econômicas, relações entre grupos - nobreza/clero/burguesia/camponeses, questões teológicas, hierarquia da igreja, sujeitos no medievo, questões ligadas à universidade, embate tchecos-alemães). Destacamos, ao longo do texto, algumas delas, considerando o modo como a alternância entre o micro e o macro permite uma maior aproximação com relação aos eventos desta viagem.

Por fim, este exercício levantou-nos reflexões no âmbito da pesquisa. A primeira é que a alternância entre o macro e o micro nos permite pensar sobre o que significa lidar com uma história de vida como microcosmo do social. A imagem que Hus faz de si é uma construção 
que não diz respeito apenas a ele e a suas escolhas, mas do quanto esse si é um constructo social que diz dos grupos aos quais ele representa. 0 macro e o micro não se explicam mutuamente, mas se interlaçam constantemente. Hus mostrou-se como um clérigo e intelectual. Assumiu o topos do mártir, em determinados momentos. Como clérigo, colocou-se no lugar de quem tem a dizer, enquanto o outro tem a ouvir. Como intelectual, colocou-se no lugar de quem tem que interpretar a realidade e oferecer esta interpretação aos outros. Lembramonos da obra magistral de Le Goff (1999), em sua biografia de São Luís, e da constante tensão, quando tratamos de figuras do Medievo, entre o indivíduo e os modelos a partir dos quais ele se vê e é visto. Embora não nos pareça que essa tensão em algum momento da história tenha deixado de existir.

A segunda é em relação ao trabalho com cartas. Cartas são documentos fragmentários, na medida em que elas foram escritas para um destinatário específico com quem o remetente compartilha códigos que, em geral, nós, os leitores não supostos, não compartilhamos. Além disso, o trabalho com cartas remete a diversas temporalidades presentes (a dos missivistas, a dos que as interceptam, a dos que as guar-

\section{Referências}

AGUIAR, Thiago Borges de. Abra esta carta após minha morte: escrita como testamento na correspondência entre Jan Hus e seu discípulo. Acta Scientiarum. Education, v. 33, p. 77-85, 2011 a.

AGUIAR, Thiago Borges de. Cartas que dizem adeus: Jan Hus, 1415. In: XXVI Simpósio Nacional de História, 2011, São Paulo. Anais do XXVI simpósio nacional da ANPUH - Associação Nacional de História. São Paulo: ANPUH-SP, 2011b. p. 1-15.

AGUIAR, Thiago Borges de. Jan Hus: cartas de um educador e seu legado imortal. São Paulo: Annablume, 2012. dam, dos editores etc.). As cartas de viagem de Hus, em especial, estão transpassadas por códigos pessoais e por temporalidades dos macroeventos históricos de seu contexto (relações seculares e imediatas entre tchecos e alemães, décadas de um Cisma Papal e suas soluções no Concílio de Constança, estruturas do Sacro Império e relações familiares entre os reis tchecos, entre outros) que fizeram parte de nossa análise, como elementos necessários para darmos conta de compreendermos um indivíduo e suas imagens.

A última, que fica como um elemento que surge para além da própria análise, aqui apresentada, é o caráter da viagem como espaço no qual a construção de uma imagem de si se torna não apenas possivel como necessária e cuidada. Isso nos parece mais forte justamente porque, no caso de Hus, não se trata apenas de uma viagem, mas de uma viagem a partir do exílio e para um lugar desconhecido. Parece-nos frutífero observar imagens de si em cartas de viagem a partir do exílio, justamente porque o remetente está questionando "quem sou eu quando não estou onde deveria estar". Talvez por isso tenha sido tão importante para Hus construir as imagens de si e dos outros, pois buscava um sentido para o seu não-lugar.

AGUIAR, Thiago Borges de; SILVA, Davi Costa da. Identidade nacional na Boêmia do século XV e a formação de uma paideia tcheca. Educação e Pesquisa, v. 41, p. 309-324, 2015.

BASTOS, Maria Helena Camara; CUNHA, Maria Teresa Santos; MIGNOT, Ana Chrystina Venancio. (Orgs.). Destinos das letras: história, educação e escrita epistolar. Passo Fundo: UPF, 2002.

DAVIS, Natalie Zemon. O retorno de Martin Guerre. Rio de Janeiro: Paz e Terra, 1987.

DOMINICÉ, Pierre. O que a vida lhes ensinou. In: NÓ- 
VOA, António; FINGER, Mathias. (Orgs.). 0 método (auto)biográfico e a formação. Natal: EDUFRN; São Paulo: Paulus, 2010. p. 191-222.

FERRAROTTI, Franco. Sobre a autonomia do método autobiográfico. In: NÓVOA, António; FINGER, Mathias. (Orgs.). 0 método (auto)biográfico e a formação. Natal: EDUFRN; São Paulo: Paulus, 2010. p. 33-57.

FREITAS, Marcos Cezar. Por quem os sinos dobram? In: BASTOS, Maria Helena Camara; CUNHA, Maria Teresa Santos; MIGNOT, Ana Chrystina Venancio. (Orgs.). Destinos das letras: história, educação e escrita epistolar. Passo Fundo: UPF, 2002. p. 57-73.

FUDGE, Thomas A. Jan Hus in english language historiography, 1863-2013. Journal of Moravian History, v. 16, n. 2, p. 90-138, 2016.

GALVÃO, Walnice Nogueira; GOTLIB, Nádia Battella. (Orgs.). Prezado senhor, prezada senhora: estudos sobre cartas. São Paulo: Companhia das Letras, 2000.

GUIMARÃES, Marcella Lopes. O pensamento eclesiológico de Jan Hus (1369-1415) e sua condenação pelo Concílio de Constança. In: José Antônio de Camargo R. de Souza; Luís Alberto De Boni. (Org.). As relações de poder: do Cisma do Ocidente a Nicolau de Cusa. Porto Alegre: Edições EST, 2011, v. 1, p. 164-182.

GINZBURG, Carlo. Mitos, emblemas e sinais: morfologia e história. São Paulo: Companhia das Letras, 1989.

GINZBURG, Carlo. Olhos de madeira: nove reflexões sobre a distância. São Paulo: Companhia das Letras, 2001.

GINZBURG, Carlo. 0 fio e os rastros: verdadeiro, falso, fictício. São Paulo: Companhia das Letras, 2006.

HALL, Michael. Raymond Chandler. In: GALVÃO, Walnice Nogueira; GOTLIB, Nádia Battella (Orgs.). Prezado senhor, prezada senhora: estudos sobre cartas. São Paulo: Companhia das Letras, 2000. p. 69-76.

LE GOFF, Jacques. São Luís - biografia. Rio de Janeiro: Record, 1999.

LE GOFF, Jacques; SCHMITT, Jean-Claude. (Coords.).
Dicionário temático do Ocidente Medieval. Volume II. Coordenação da Tradução Hilário Franco Júnior. Bauru, SP: Edusc, 2006.

LIMA, Sonia Maria van Dijck; FIGUEIREDO JÚNIOR, Nestor. De Gilberto Freyre para José Lins do Rego. In: GALVÃO, Walnice Nogueira; GOTLIB, Nádia Battella. (Orgs.). Prezado senhor, prezada senhora: estudos sobre cartas. São Paulo: Companhia das Letras, 2000. p. 241-250.

MIGNOT, Ana Chrystina Venâncio. Artesãos da palavra: cartas a um prisioneiro político tecem redes de ideias e afetos. In: BASTOS, Maria Helena Camara; CUNHA, Maria Teresa Santos; MIGNOT, Ana Chrystina Venancio. (Orgs.). Destinos das letras: história, educação e escrita epistolar. Passo Fundo: UPF, 2002. p. $115-136$.

NASCIMENTO, R. C. S.. Cartas de Jan Hus: Indícios de uma intenção educativa. Maringá-PR: RBHE- Revista Brasileira de História da Educação, v. 15, n. 2 (38), p. 309-314, maio/ago 2015 (Resenha).

NÓVOA, António; FINGER, Mathias. (Orgs.). 0 método (auto)biográfico e a formação. Natal: EDUFRN; São Paulo: Paulus, 2010.

NOVOTNÝ, Václav. M. Jana Husi Korespondence a dokumenty. Praga: Komise pro vydávání pramenů náboženského hnutí českého, 1920.

SCALES, Leonard. At the margin of community: germans in pre-hussite Bohemia. Transactions of the Royal Historical Society, v. 9, p. 327-352, 1999.

SPINKA, Matthew. John Hus: a biography. Princetown, New Jersey, EUA: Princetown University Press, 1968.

SPINKA, Matthew. (Ed.). The letters of John Hus. Manchester, USA: Manchester University Press, 1972.

TIN, Emerson. (Org.). A arte de escrever cartas. Campinas: Editora da Unicamp, 2005.

Recebido em: 28.03.2017

Aprovado em: 23.07.2017 
Thiago Borges de Aguiar é Doutor em Educação pela Universidade de São Paulo. Professor do Programa de Pós-Graduação em Educação da Universidade Metodista de Piracicaba. e-mail: tbaguiar@unimep.br

Universidade Metodista de Piracicaba - UNIMEP

Programa de Pós-Graduação em Educação - Bloco 07 - Campus Taquaral - Rodovia do Açúcar, no 7000 - KM 156

Caixa Postal 68 - 13.423-170 - Piracicaba - SP

Telefone: (19) 3124-1617 